\title{
Coordination of morphological and physiological traits in naturally recruited Abies alba Mill. saplings: insights from a structural equation modeling approach
}

\author{
Angelo Rita $^{1,2}$ - Francesco Ripullone ${ }^{1}$ - Tiziana Gentilesca ${ }^{1}$ - Luigi Todaro ${ }^{1}$. \\ Antonio Saracino $^{2} \cdot$ Marco Borghetti $^{1}$
}

Received: 18 March 2017 / Accepted: 13 June 2017 /Published online: 23 June 2017

(C) INRA and Springer-Verlag France SAS 2017

\begin{abstract}
- Key message Apical dominance ratio (ADR), reported as a suitable indicator for the growth and development of Abies alba, is concurrently determined by morphological and functional plant traits. Structural equation modeling (SEM) proved here to be an effective multivariate technique to represent the contribution of different variables in explaining ADR variability.

- Context During the natural recruitment of understory tree saplings, the light environment and competition among individuals may change drastically as well as their growth patterns. To cope with this, saplings have a remarkable ability to accordingly modify their physiology and morphology. Therefore, understanding the ecological significance of plant
\end{abstract}

\section{Handling Editor: Marcus Schaub}

Contribution of the co-authors A Rita conceived the study, conceptualized and performed the analysis, and wrote the manuscript. F Ripullone and $\mathrm{T}$ Gentilesca carried out the measurements and raw data preparation, contributed to discussing and interpreting the data at all stages, and participated in paper writing. L Todaro and A Saracino participated in data discussion and paper writing. M Borghetti participated in data discussion and paper writing and provided editorial advice.

Electronic supplementary materialThe online version of this article (doi:10.1007/s13595-017-0653-y) contains supplementary material, which is available to authorized users.

Angelo Rita

angelo.rita@unibas.it

Francesco Ripullone

francesco.ripullone@unibas.it

Tiziana Gentilesca

tiziana.gentilesca@unibas.it

Luigi Todaro

luigi.todaro@unibas.it structural patterns requires an integrated view of morphological, architectural, and physiological attributes of plants.

- Aims Here, we applied a SEM approach to understand the mechanisms influencing the ADR, recently reported as suitable indicator of the growth conditions favoring silver fir (Abies alba Mill.) natural regeneration in Mediterranean areas. - Methods A series of plant traits (e.g., root-collar diameter, leaf mass per area, and isotope composition) were combined into two main latent variables, namely Morphology and Physiology, to account for their relative contribution in explaining the ADR variability.

- Results Our results underline the importance of variables accounting for the photosynthetic capacity and leaf economics in determining ADR; among them, leaf mass per area (LMA) emerged as an important driving variable.

- Conclusion SEM proved to be an effective multivariate technique to represent the coordination of different morphological and functional variables in explaining ADR variability in silver fir.

Keywords Structural equation modeling · Sapling · Path analysis $\cdot$ Functional traits $\cdot$ Apical dominance ratio

\author{
Antonio Saracino \\ a.saracino@unina.it \\ Marco Borghetti \\ marco.borghetti@unibas.it
}

1 Scuola di Scienze Agrarie, Forestali, Alimentari ed Ambientali, Università della Basilicata, Viale dell'Ateneo Lucano 10, 85100 Potenza, Italy

2 Dipartimento di Agraria, Università di Napoli Federico II, Via Università 100, 80055 Portici, Italy 


\section{Introduction}

In recent years, the functional traits of plants - their morphological, anatomical, physiological, biochemical, and phenological characteristics - have been broadly used in research on evolutionary biology as well as community and functional ecology (see Westoby and Wright 2006 for a review). These traits are known to drive ecosystem processes, to influence plant performance in a given environmental setting, and to offer the most promising path to understand how vegetation properties and function change along key ecological gradients (e.g., McGill et al. 2006).

Presently, several comparative studies show these aspects of tree structure and function. For instance, McDowell et al. (2011) used a record of isotopic composition instead of physical structure to infer past physiology. They found a general decline in stable carbon isotope discrimination with increasing height of several species for both foliar and wood material. Furthermore, Olson et al. (2014) found a universal scaling between height and anatomical functional structure (i.e., hydraulic diameter). Marshall and Monserud (2003) and Fellner et al. (2016) found that specific leaf area (SLA) is tightly linked to canopy structure in many conifer species.

To date the survival phase and growth performance of tree saplings are both considered as the key bottleneck in the natural recruitment dynamics of understory saplings (Walters and Reich 2000; Sánchez-Gómez et al. 2006). This pattern of recruitment is the result of a wide range of interacting environmental factors that includes yearly variation in micro-site climate, changes in the physical environment (e.g., topography and soils), and different biotic factors (e.g., ungulates browsing, insect, and pathogens attack) (Dobrowolska 2010). Therefore, a pressing challenge in ecological studies is to better understand the complex structure and dynamics of tree recruitment to formulate appropriate silvicultural regime that promote the natural evolutionary processes and maintain heterogeneous conditions, particularly in mixed forest stands (Cater and Levanic 2013).

Many recent studies have explored the intraspecific variation of understory vegetation to highlight a large, informative set of morphological, anatomical, and physiological plant traits (e.g., Dobrowolska 2008; Duchesneau et al. 2001; Grassi and Giannini 2005). Among these, tree height is likely considered the most informative expression of growth and competitive ability of understory tree saplings. Indeed, height change is affected by important processes such as leaf expansion and shoot extension (Meinzer et al. 2008), rates of photosynthesis (Hubbard et al. 1999), and mechanical influences of radial growth (Enquist 2002).

The above-cited literature has provided general empirical equations that establish basic relationships among these variables across species (see Online Resource Tab. OR1 for a review). Many of these studies have dealt with the relationships of anatomical and physiological features by using simple bivariate approaches, while few of them scaled up to multivariate ones, which are capable of accounting for the complexity of the relationships among variables. Indeed, many changes in tree structure and function occurring throughout ontogeny likely involve trade-offs (i.e., the planttraits syndrome) which are difficult to discern. This can be seen, for example with the cost of constructing xylem conduit walls that provide a twofold function (i.e., hydraulic conductivity and mechanical stability of trees). Thus, we may be easily misled by preconceptions that a given trait is affected by a single factor when in reality additional factors may play an important role. Therefore, although multiple regression is sometimes used to examine interacting traits (e.g., Rüger et al. 2012), this statistical method is not a robust way to test different functional hypotheses (Shipley et al. 2005).

An active research area investigates the interrelations among plant traits (e.g., Grace et al. 2010; Shipley et al. 2005) by quantifying their correlations to understand the processes that drive the dynamics of complex natural ecosystems via structural equation modeling (SEM). SEM is a multivariate technique that can test both direct and indirect effects of multiple interacting factors. Moreover, it has proven to be a powerful tool to explore and contrast non-exclusive hypotheses of relationships among variables by using observational data (Shipley et al. 2005; Grace et al. 2010). Unlike classic multivariate approaches, such as the principal component analysis (PCA, see for instance Albert et al. 2010), which reduces multiple observed variables into fewer components, SEM is able to represent complex attributes (i.e., latent) that cannot be measured directly but can be estimated from observed variables (Spasojevic et al. 2014). Promising results were recently obtained using the SEM approach: its range of applications includes studies on forest community composition (Clark et al. 2007; Laughlin and Abella 2007), ecosystem services (Lavorel and Grigulis 2012), forest resilience (Camarero et al. 2015), and functional ecology (Shipley et al. 2005; Spasojevic et al. 2014). In forest studies, key traits of seed size, leaf size, tree height, leaf mass per area, and wood density, in addition to structural canopy properties and photosynthetic performance, are among the variables found strongly associated with plant functional strategies (Shipley et al. 2006). For instance, Meziane and Shipley (2001) presented a path model relating interspecific patterns between specific leaf area, leaf nitrogen content, net photosynthesis, and stomatal conductance. They found that specific leaf area is the main variable directly affecting both leaf nitrogen levels and net photosynthetic rates.

In this regard, several authors have shown that apical dominance ratio (ADR, i.e., the length of the apical shoot divided by the mean length of the lateral shoots at the last node) is a good proxy for the growth and development of silver fir (Abies alba Mill.) saplings when exposed to different light 
conditions (Grassi and Giannini 2005; Dobrowolska 2008). Among other attributes, ADR drew wide interest because of its ability to reflect plant micro-environmental features and to provide basic input in the prediction of understory tree growth and survival rates (e.g., Duchesneau et al. 2001). Therefore, ADR could be considered a useful tool for forest managers in monitoring stand dynamics. In practice, ADR is much easier to measure when forest managers have to decide which types of sapling should be favored by silviculture treatments in order to promote the regeneration establishment.

In this study, the main objective was to explore the potential of a SEM approach in representing the coordination among set of morphological and functional traits in silver fir plants; in particular, we tried to answer the following question: defining synthetic latent variables in a SEM approach could be an effective tool to get more insight into processes that drives ADR variability in a silver fir saplings population? Could this be considered a useful step towards helpful modeling of silver fir natural regeneration? For our model exercise, we used the silver fir saplings cohorts investigated by Ripullone et al. (2016) growing on Monte Pollino (Southern Italy), which was one of the most important refugial areas for silver fir in the glacial period and still retains high conservation value for this species (Piotti et al. 2017).

\section{Materials and methods}

\subsection{Experimental site and data collection}

The main data came from an experiment carried out recently by Ripullone et al. (2016), which surveyed a silver fir natural regeneration plot within the Pollino National Park $\left(39^{\circ} 07^{\prime} \mathrm{N}\right.$; $16^{\circ} 13^{\prime} \mathrm{E} ; 1350 \mathrm{~m}$ a.s.1.), Southern Italy. At the study site, the climate is typical of the Mediterranean area and characterized by average annual temperature ranging from 7 to $12{ }^{\circ} \mathrm{C}$ over the last 30 years and total annual precipitation exceeding $1100 \mathrm{~mm}$, distributed mainly in autumn and winter. Extended summer droughts are typically characterized by only $7.6 \%$ precipitation falling during summer months (temperature data collected from Castrovillari $\left[39^{\circ} 83^{\prime} \mathrm{N}, 16^{\circ} 19^{\prime} \mathrm{E}\right]$ and precipitation from Campotenese $\left[39^{\circ} 51^{\prime} \mathrm{N}, 16^{\circ} 05^{\prime} \mathrm{E}\right]$ meteorological stations).

In this area, A. alba underwent a sharp contraction in its spatial distribution (Piotti et al. 2017), mainly caused by the systematic and indiscriminate harvesting exerted over the past century (i.e., 1920-1950), where this species was mostly used for shipbuilding and timber framing (Iovino and Menguzzato 1993). Because of this selective pressure, currently there are only a few hundred large trees (i.e., more than $80 \mathrm{~cm}$ diameter at breast height and $35 \mathrm{~m}$ height, and $\sim 150$ years old) and very few regeneration groups left within the Pollino territory. These groups are struggling to establish themselves, compared to more competitive species such as oak (Quercus cerris L.) and beech (Fagus sylvatica L.). The stands examined in this study can be described as the sub-association "AbietiFagetum", variant of mesophilic "Physospermo verticillatiQuercetum cerridis" (Di Pietro and Fascetti 2005).

The A. alba regeneration groups are mostly located in small canopy gaps formed by the collapse of senescent trees or grow at the margin of forestry roads where light conditions become more favorable for their establishment. Although, this is considered a highly shade-tolerant tree among the European forest species, especially at the juvenile stage, the peculiar structure and composition of these communities create a screen that considerably reduce the light penetration through the canopy. This negatively affects the survival and establishment of A. alba seedlings.

In this area, we selected a survey plot $(5 \times 50 \mathrm{~m})$, where $A$. alba is mixed with $F$. sylvatica (i.e., 40 and $60 \%$, respectively) at the canopy layer; whereas it constitutes more than $90 \%$ of the understory vegetation. A set of measurements was carried out between June and October in 2012 (i.e., at the end of the growing season) (see Table 1). The leaf area index (LAI) was measured twice, in July and August 2012, respectively, using the LAI-2000 "Plant Canopy Analyzer" (LI-COR, Lincoln, Nebraska, USA). Below-canopy readings were conducted at a height of $1.3 \mathrm{~m}$ above ground from the $\mathrm{SE}$ to the NW corner and replicated three times at sunset in diffuse light conditions. In general, the observed LAI values $(3.9 \pm 0.4$, mean value and SE) refer to medium shading conditions. Height, root collar diameter (RCD), and lengths of the leading shoot and twigs forming the upper whorl were measured on 41 saplings. Subsequently, the ADR was calculated according to Grassi and Giannini (2005). Moreover, needles from a lateral current-year shoot of the first whorl per sapling were also sampled at the end of the experiment, measured for their projected area, and then oven-dried to a constant weight for determination of leaf mass per area (LMA, $\mathrm{g} \mathrm{m}^{-2}$ ). At the beginning of October 2012, lateral current-year shoots of the first whorl were taken from each sapling for determination of carbon $\left(\delta^{13} \mathrm{C}\right)$, oxygen $\left(\delta_{18} \mathrm{O}\right)$, and nitrogen $\left(\delta^{15} \mathrm{~N}\right)$ isotope compositions. For further details, please see Ripullone et al. (2016).

\subsection{Model specification}

Understanding the ecological significance of architectural attributes requires an integrated view of morphological and physiological traits of plants in a given environment. To this aim, we developed a priori conceptual structural equation model presented in Fig. 1 based on the abovementioned hypothesis.

Variables tracking the suite of morphological and structural properties (Morph, morphology) and leaf physiology and photosynthesis (Phys, physiology) are represented as latent, i.e., unmeasured, conceptual variables. Each latent variable was 
Table 1 Descriptive statistic of the measured variables

\begin{tabular}{|c|c|c|c|c|c|c|c|}
\hline \multirow[t]{2}{*}{ Variable } & \multirow[t]{2}{*}{ Mean } & \multirow[t]{2}{*}{ SD } & \multicolumn{5}{|c|}{ Quantiles } \\
\hline & & & $0 \%$ & $25 \%$ & $50 \%$ & $75 \%$ & $100 \%$ \\
\hline $\mathrm{RCD}(\mathrm{cm})$ & 2.46 & 1.49 & 0.15 & 1.20 & 2.30 & 3.70 & 6.00 \\
\hline Height (m) & 1.41 & 0.82 & 0.27 & 0.83 & 1.21 & 1.90 & 3.2 \\
\hline $\mathrm{ADR}$ & 0.68 & 0.35 & 0.14 & 0.39 & 0.65 & 0.94 & 1.34 \\
\hline Shoot $(\mathrm{cm})$ & 34.60 & 27.21 & 5.00 & 16.00 & 23.50 & 54.00 & 116.00 \\
\hline $\mathrm{NL}_{\text {Shoot }}$ (no.) & 2.56 & 1.12 & 1.00 & 2.00 & 2.00 & 3.00 & 5.00 \\
\hline LMA $\left(\mathrm{g} \mathrm{m}^{-2}\right)$ & 136.90 & 45.42 & 46.73 & 106.30 & 128.39 & 170.58 & 227.03 \\
\hline$\delta^{13} \mathrm{C}(\% \circ)$ & -31.65 & 1.03 & -33.41 & -32.40 & -31.84 & -31.03 & -29.10 \\
\hline$\delta^{18} \mathrm{O}(\% 0)$ & 30.29 & 0.85 & 27.60 & 29.95 & 30.40 & 30.85 & 31.80 \\
\hline$\delta^{15} \mathrm{~N}(\% \circ)$ & -1.48 & 1.35 & -5.42 & -2.28 & -1.33 & -0.76 & 1.05 \\
\hline $\mathrm{N}_{\text {leaf }}(\%)$ & 1.34 & 0.20 & 0.90 & 1.18 & 1.34 & 1.43 & 1.73 \\
\hline
\end{tabular}

Shoot total length of lateral shoots, $N L_{\text {Shoot }}$ number of shoots, $R C D$ root collar diameter, $A D R$ apical dominance ratio, LMA leaf mass area, $\delta^{13} C$ carbon isotope composition, $\delta^{18} O$ oxygen isotope composition, $\delta^{15} N$ nitrogen isotope composition, $N_{\text {leaf }}$ leaf nitrogen content defined by a set of measurements, in particular, the RCD, total length of the lateral shoots (Shoot), and number of the lateral shoots $\left(\mathrm{NL}_{\text {Shoot }}\right)$ were selected as indicators of Morph. Specifically, RCD was considered a good indicator of sapling growth potential (i.e., the tree-specific potential to achieve a certain growth rate) and a generalized proxy of root system size (Mexal and Landis 1990; Thompson 1985), whereas Shoot and $\mathrm{NL}_{\text {Shoot }}$ could be interpreted as proxies for growth form and competitiveness with respect to light availability (Grossnickle et al. 1991).

It is well established that the observed isotope discrimination in leaf, that reflects the balance between the leaf photosynthetic capacity and its stomatal conductance, is very sensitive to environmental conditions such as light regimes, and in turn on ADR (Yakir and Israeli 1995; Ripullone et al. 2016). Therefore, based on a semi-empirical approach, Phys was defined by the LMA, leaf nitrogen content $\left(\mathrm{N}_{\text {leaf }}\right), \delta^{13} \mathrm{C}, \delta^{18} \mathrm{O}$, and $\delta^{15} \mathrm{~N}$ isotope compositions. LMA and $\mathrm{N}_{\text {leaf }}$ were used as predictors of the photosynthetic capacity of trees per unit of leaf area (Poorter et al. 2009). The $\delta^{13} \mathrm{C}, \delta^{18} \mathrm{O}$, and $\delta^{15} \mathrm{~N}$ values were considered as proxies for intrinsic water-use efficiency (i.e., the ratio between the amount of carbon assimilation and stomatal conductance, Farquhar et al. 1989), leaf transpiration (Barbour and Farquhar 2000), and nitrogen load (Tcherkez and Hodges 2008), respectively.

The model accounted for the combined indirect effects between latent variables, which were then regressed against sapling ADR.

\subsection{Parameter estimation}

Parameters were estimated by comparing the actual covariance matrix, which represented the relationships between variables and the estimated covariance matrices of the best-fitting model. The model was run with the library "lavaan" (v. 0.5-
20, Rosseel 2012) in the $R$ statistical suite v. 3.2.3 (Development Core Team 2015).

The estimation method was based on finding the parameters that make the predicted covariance matrix as close as possible to the observed covariance matrix; in other words, we tried to minimize a discrepancy (badness-of-fit) function between the model predicted covariance matrix and the observed covariance matrix. According to Olsson et al. (2000), we used the most common estimation method, maximum likelihood (ML), which provides more realistic fit indexes and less biased parameter values compared to GLS (generalized least squares) and WLS (weighted least squares). As the chisquare $\left(\chi^{2}\right)$ is usually inflated by non-normal data distribution, the Satorra-Bentler correction (Satorra and Bentler 1994) was applied to rescale values of the ML-based chi-square by an amount that reflected the degree of kurtosis in the distribution. In order to quantify the uncertainty in the estimates of the SEM model caused by the reduced sample size, a bootstrapped confidence interval based on 1000 replications was also calculated via bootstrapLavaan() function.

\subsection{Testing model fit}

The goodness-of-fit chi-square ( $\left.\chi^{2} \mathrm{GoF}\right)$ statistic was used to test the overall quality of the model fit. Traditionally, it assesses the magnitude of discrepancy between the sample and fitted covariance matrices: the null hypothesis is that the observed and predicted covariance matrices are identical $(\mathrm{Hu}$ and Bentler 1999). If this null hypothesis is true, then the ML chi-squared statistic is asymptotically distributed according to a chi-squared distribution with the appropriate degrees of freedom. Thus, a $\chi^{2}$ value with a small $(P<0.05)$ probability under the null hypothesis allows us to reject the model. Residuals and modification indexes were examined to determine whether or not there were apparent model-data 
Fig. 1 Structural equation model (SEM) for the formulated hypothesis. Initial conceptual (a priori) model. Latent variables are enclosed in circular nodes and indicated (estimated) by measured or indicator variables shown in square nodes. Arrows represent possible path coefficients. $R C D$ root collar diameter, Shoot total length of the lateral shoots, $N L_{\text {Shoot }}$ number of the lateral shoots, LMA leaf mass per area, $N_{\text {leaf }}$ leaf nitrogen content, $\delta^{13} C$ carbon isotope composition, $\delta^{18} \mathrm{O}$ oxygen isotope composition, $\delta^{15} \mathrm{~N}$ nitrogen isotope composition

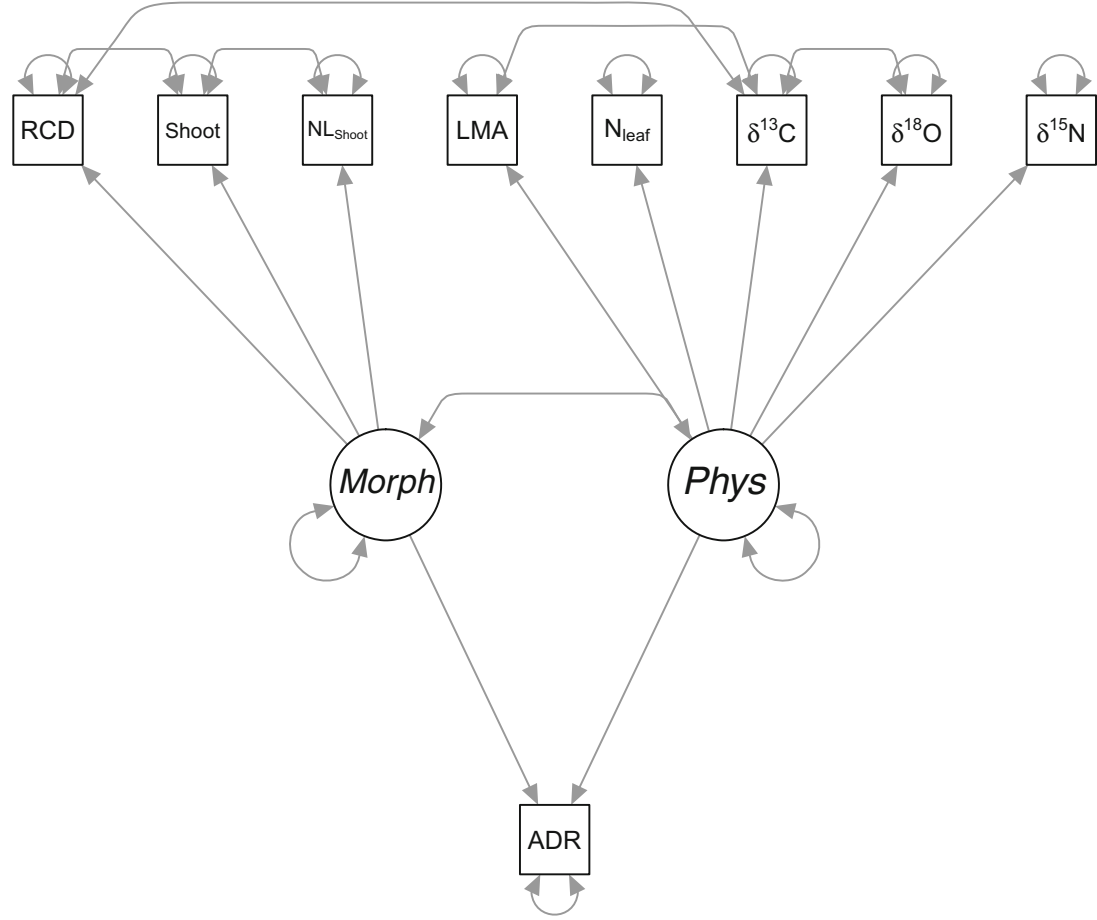

discrepancies, which in turn were used to identify alternative models for consideration.

Since the interpretation of the chi-square statistics is limited by both conceptual (i.e., the hypothesis of perfect fit is unreasonable) and practical (i.e., chi-square test is sensitive to sample size) reasons, the closeness-of-fit was also assessed by a combination of more informative fit indexes. In particular, Bentler's comparative fit index (CFI; Bentler 1990) is an incremental index that measures the relative improvement in the fitted in comparison to baseline model (i.e., the independent model). The CFI performs well even when sample size is small; its values range between 0 and 1 , and values $>0.9$ indicate an acceptable fit of the model to the data. The root mean square error of approximation (RMSEA; Steiger 1990) is based on the predicted vs. observed covariance matrix, and it is a parsimonycorrected index that accounts for model complexity. Thus, RMSEA measures the degree of misspecification per model degree of freedom, adjusted according to its sample size. Browne and Cudeck (1992) suggested that an RMSEA $\leq 0.05$ indicates a close approximation fit, a value between 0.05 and 0.08 indicates a reasonable approximation, and a value $\geq 0.1$ suggests a poor fit.

The standardized root mean square residual (SRMR) is a measure of the mean absolute correlation residual, which is simply the overall difference between the observed and predicted correlation matrices. Hu and Bentler (1999) proposed a threshold of SRMR $\leq 0.08$ for acceptable fit. In addition, the significance of each pathway was evaluated with a $t$ test that used the unstandardized coefficients.

\section{Results}

The goodness-of-fit tests indicated that the model adequately described the relationships between variables, corroborating the underlying hypothesis of relationships between the latent and observed variables. Hence, there were no grounds for rejecting the fitted model. Nonetheless, for clarity, we only report the standardized path coefficients in Fig. 2 and present the unstandardized ones and standard errors in the Online Resource Tab. OR2.

The final formulated model (Fig. 2) converged with statistics indicating a relatively good overall model fit $\left(\chi^{2}=23.19\right.$, d.f. $=20, P=0.288$ ). Additional model fit statistics are in agreement with the closeness-of-fit hypothesis: $\mathrm{CFI}=0.980$, RMSEA $=0.068$, and SRMR $=0.082$. These results emphasize the many significant direct and indirect effects linked to $\mathrm{ADR}$, and the complex relationships between the processes involved. In particular, the positive contribution of both Morph and Phys to ADR was supported by their statistically significant paths ( 0.51 and 0.41 in terms of standardized units, respectively). In addition, the combined indirect effects between latent variables (i.e., covariance between Morph and Phys) were also statistically significant.

Inspection of the $z$ values revealed that, except for $\delta^{15} \mathrm{~N}$, each observed variable significantly contributed in the loading of its respective latent variable (see Online Resource Tab. OR2 for detailed statistics). Interestingly, we found that LMA emerged as a driving variable among the physiological traits, according to the standardized coefficient (Fig. 2 and Online Resource Tab. OR2). 
Fig. 2 Final specific model for the formulated hypothesis. Square nodes indicate manifest variables, circular nodes indicate latent variables, and triangular nodes indicate constant variables (intercepts). The path coefficients represent standardized partial regression coefficients. Directed edges indicate linear regression parameters and bidirectional edges indicate (co)variances. $R C D$ root collar diameter, Shoot total length of the lateral shoots, $N L_{\text {Shoot }}$ number of the lateral shoots, $L M A$ leaf mass per area, $N_{\text {leaf }}$ leaf nitrogen content, $\delta^{13} C$ carbon isotope composition, $\delta^{18} \mathrm{O}$ oxygen isotope composition, $\delta^{15} N$ nitrogen isotope composition

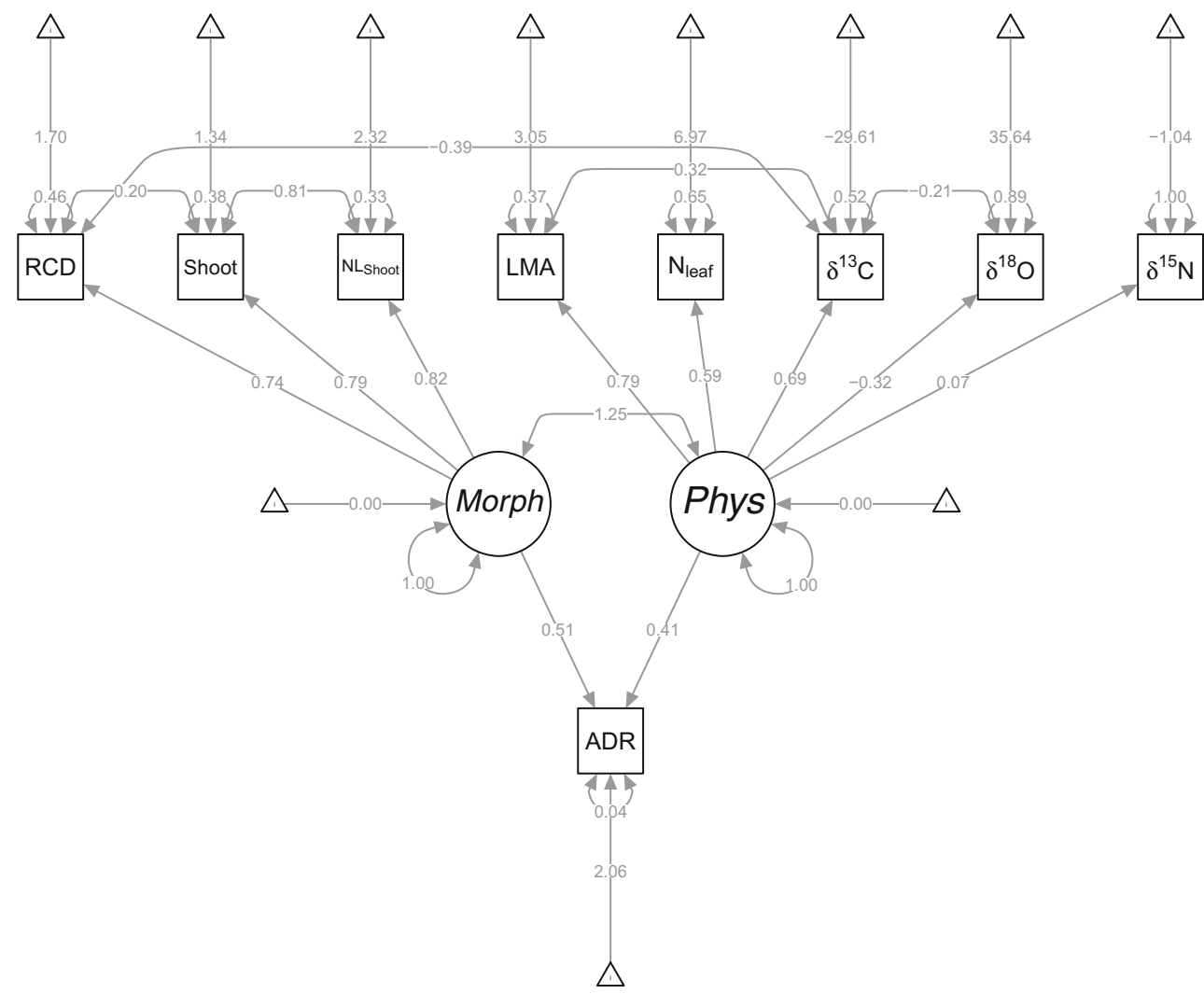

As expected, when bootstrap resampling was applied, a general weakening, in terms of significance of the relationships among paths, was observed, corresponding to an increase in the standard errors. This is consistent with previous findings highlighting inaccurate bootstrapped results in the presence of a small sample size (Nevitt and Hancock 2001).

Considering all the predicted direct and indirect effects, the full fitted model explained almost all of the observed variability in $\operatorname{ADR}\left(R^{2}=0.96\right)$.

\section{Discussion}

It has long been recognized that the recruitment dynamics of Mediterranean species, including silver fir populations, is largely influenced by the combination of resource availability (i.e., mainly local water and light conditions) and individual responses to disturbance, which together likely drive the survivorship and growth of saplings (Linares and Carreira 2009; Ameztegui and Coll 2011). For this reason, several studies have sought out a quantitative description of the interactions between environmental variables and functional plant traits, in order to assess the ability of saplings to cope with certain environmental constraints (see Online Resource Tab. OR1). To date, evidence for the physiological or morphological plasticity of saplings' apical dominance has been reported with respect to light conditions (e.g., Duchesneau et al. 2001; Grassi and Giannini 2005). In particular, ADR in silver fir is known to have positive relationships with relative irradiance (up to $35 \%$ of RI, see Grassi and Giannini 2005), radial growth, and water-use efficiency - this has lent support to using ADR as a suitable proxy of the growth conditions favoring silver fir natural regeneration (see, for instance, Dobrowolska 2008). However, inference drawn from the functional linkages between plant morphology and physiology on ADR is limited, probably in part because the multiple regression analysis approach is not able to rigorously test these functional hypotheses (Shipley et al. 2005). To date, our study is one of the few attempts that has successfully linked a suite of plant interacting traits through a SEM approach (e.g., Meziane and Shipley 2001; Shipley et al. 2005).

The picture that emerges from such an analysis is that our model well explained the interacting contributes of morphological and physiological traits known to affect the ADR (Fig. 2). This is in agreement with the results of Küppers (1994) and Valladares and Niinemets (2007), who stated, respectively, that plant physiology and morphology alone might not fully explain the ecological performance of saplings in the field.

There is a number of specific considerations that can be drawn from our model exercise and its results. For example, 
morphological attributes likely best explain the ADR variability. In particular, the strength of both Shoot and $\mathrm{NL}_{\text {Shoot }}$ variables in loading Morph may be attributed to the "wellknown" control exerted by the apex over the lateral bud outgrowth (Hillman 1984). Further, the path significance confirms that sapling RCD is a good predictor of ADR, as found elsewhere in many studies (e.g., Dobrowolska 2008, among the others). Indeed, size-dependent models of tree growth strongly suggest that RCD is a reliable proxy for height growth potential and for whole-tree performance (King 1990; lida et al. 2014). Nonetheless, while confirming this relationship, our model also suggests that a full understanding of the linkages between RCD and ADR requires the indirect consideration of other morphological and physiological plant traits. In particular, the expected negative relationship between $\delta^{13} \mathrm{C}$ (i.e., intrinsic water-use efficiency) and RCD (Fig. 2) presumably reflects the attitude of this species to modify the photosynthesis/stomatal conductance ratio (Farquhar et al. 1989).

Photosynthetic variables and leaf economics (sensu Wright et al. 2004), generally thought to be of paramount importance for plant performance, had significant relationships with the ADR parameter (Fig. 2). The LMA is one of the most widely used plant physiological traits due to its easy measurability and its sound theoretical framework. Comprehensive studies underscored how higher LMA is linked to greater photosynthetic capacity in adequate light conditions for sapling growth (Niinemets et al. 1998), thus underlying its ability to reveal key physiological information. In particular, for silver fir saplings, positive relationships were consistently reported between LMA and ADR values under different light conditions (i.e., difference in thickness between sun vs. shade leaves) (Robakowski et al. 2004; Grassi and Giannini 2005). Our SEM model quantified the linkage between LMA and ADR, and further suggested a significant covariance between LMA and $\delta^{13} \mathrm{C}$. In fact, several authors (Meziane and Shipley 2001; Shipley et al. 2005; Poorter et al. 2009) have already suggested that LMA alone could not serve as the best predictor of plant performance if it is not considered in tandem with the suite of interconnected physiological traits.

In this context, our examination of the entire structure of interacting plant trait variables revealed intriguing contrasting relationship between LMA, $\delta{ }^{13} \mathrm{C}$, and ADR. In particular, LMA increased with both an increase in height of the sapling crown and in light intensity, indicating that more mass is allocated per light intercepting unit area in the upper crown, where light intensity is greatest (Niinemets et al. 1998; Poorter et al. 2009). Conversely, for $\delta^{13} \mathrm{C}$, a positive relationship was not expected with ADR (and consequently with LMA) (Farquhar et al. 1989). Such paths could be perceived as counterintuitive and may lead to a misinterpretation of the results in a linear regression model, as neither LMA nor ADR would positively vary with $\delta^{13} \mathrm{C}$. In fact, this pattern was found in several studies of evergreen tree species (Ambrose et al. 2009; Warren et al. 2003) and had been interpreted as the effect of decreasing leaf mesoporosity with increasing tree height. This leads to slower $\mathrm{CO}_{2}$ diffusion from intercellular spaces to carboxylation sites, thus reducing the photosynthetic rate per leaf area and thereby contributing to high $\delta^{13} \mathrm{C}$ values.

Besides these specific findings, the success of our SEM model in explaining patterns of ADR led us to more interesting general considerations. In the published literature, adaptive traits, which are shown to reflect plant fitness, are modulated by a number of physiological and morphological adjustments (e.g., Zanne and Falster 2010; Olson et al. 2014). Among them, tree height represents an integrative long-term response to multiple ecophysiological constraints, as driven by the prevailing site-specific light conditions (SánchezGómez et al. 2006). For instance, the understory dynamic of many coniferous saplings was strictly related to the long-term interplay between available light and growth rates (Claveau et al. 2002). Although it might be very important for a species regeneration strategy, the height of saplings is a weak predictor of adult growth rates (Moles et al. 2004). Given the behavior of silver fir in the Mediterranean environment, where its shade-adapted saplings exhibit a remarkable ability to survive for a long time with very low growth rates (Aussenac 2002), the ADR, instead of tree height, may be considered a useful indicator of the phenotypic plasticity of fir saplings. The greater peculiarity of ADR, and its strength, lies in capturing in a single variable the short-term performances of trees in response to changing ecological conditions. However, we acknowledge our model exercise was limited to a single site, and it should be applied to a wide range of well-defined site conditions for more general ecological interpretations.

Therefore, based on the insights from our model, we argue that if ADR is associated with the potential of the species in the vertical light gradient (Dobrowolska 2008; Grassi and Giannini 2005; Ripullone et al. 2016), then morphology could represent the total cost in terms of resource investment to ensure both mechanical stability and a suitable space arrangement (King 1990), while physiology could represent the photosynthetic efficiency of plants (Givnish 1995). Then, the relationship between morphology and physiology may be interpreted in terms of a synergism likely to influence the fitness of understory woody plants under different conditions of light availability (Küppers 1989; Westoby and Wright 2006). However, such a relationship should not be interpreted from a simple mechanistic point of view, because many physiological processes are more plastic compared to the structural ones (Valladares et al. 2000); that is, in the short term, physiology can vary significantly without apparent changes in morphology. For example, short-term variations in photosynthesis in response to environmental constraints have little impact on shoot development. Other relevant studies reported that the difference in plasticity between morphological and physiological traits seems to be species-specific; in particular, 
the shade-intolerant species show greater physiological plasticity, whereas the more shade-tolerant species show greater morphological one (Sánchez-Gómez et al. 2006).

\section{Conclusions}

SEM proved to be an effective multivariate technique to represent the coordination of different morphological and functional variables in explaining ADR variability in silver fir. We showed, in particular, its ability to take into account the magnitude of direct and indirect effects of multiple interacting variables. Overall, our results underline the importance of variables accounting for the photosynthetic capacity and leaf economics in determining ADR; among them, LMA emerged as an important driving variable for ADR.

Acknowledgments The authors gratefully acknowledge S. Epskamp (http://sachaepskamp.com/) for the support in the SemPlot troubleshooting and A. Lapolla (Università della Basilicata, Potenza, Italy) for the precious help in conducting the fieldwork.

\section{Compliance with ethical standards}

Funding This work was supported financially by the MIUR-PRIN "Global change effects on the productivity and radiative forcing of Italian forests: a novel retrospective, experimental and prognostic analysis" [grant number 2012E3F3LK] and by the Pollino National Park, Rotonda, Italy, in the framework of the project "Un laboratorio naturale permanente nel Parco Nazionale del Pollino"

\section{References}

Albert CH, Thuiller W, Yoccoz NG, Douzet R, Aubert S, Lavorel S (2010) A multi-trait approach reveals the structure and the relative importance of intra- vs. interspecific variability in plant traits. Funct Ecol 24(6):1192-1201

Ambrose AR, Sillett SC, Dawson TE (2009) Effects of tree height on branch hydraulics, leaf structure and gas exchange in California redwoods. Plant Cell Environ 32(7):743-757

Ameztegui A, Coll L (2011) Tree dynamics and co-existence in the montane-sub-alpine ecotone: the role of different light-induced strategies. J Veg Sci 22(6):1049-1061

Aussenac G (2002) Ecology and ecophysiology of circum-Mediterranean firs in the context of climate change. Ann For Sci 59:823-832

Barbour MM, Farquhar GD (2000) Relative humidity- and ABA-induced variation in carbon and oxygen isotope ratios of cotton leaves. Plant Cell Environ 23(5):473-485

Bentler PM (1990) Comparative fit indexes in structural models. Psychol Bull 107(2):238

Browne MW, Cudeck R (1992) Alternative ways of assessing model fit. Sociol Methods Res 21(2):230-258

Camarero JJ, Gazol A, Sangüesa-Barreda G, Oliva J, Vicente-Serrano SM (2015) To die or not to die: early warnings of tree dieback in response to a severe drought. J Ecol 103(1):44-57

Cater M, Levanic T (2013) Response of Fagus sylvatica L. and Abies alba Mill. in different silvicultural systems of the high Dinaric karst. For Ecol Manag 289:278-288
Clark CM, Cleland EE, Collins SL, Fargione JE, Gough L, Gross KL, Pennings SC, Suding KN, Grace JB (2007) Environmental and plant community determinants of species loss following nitrogen enrichment. Ecol Lett 10(7):596-607. doi:10.1111/j.1461-0248.2007.01053.x

Claveau Y, Messier C, Comeau PG, Koates KD (2002) Growth and crown morphological responses of boreal conifer seedlings and saplings with contrasting shade tolerance to a gradient of light and height. Can J For Res 32:458-468

Di Pietro R, Fascetti S (2005) Contribute to knowledge of Abies alba Miller woodlands within the Lucanian Apennines. Fitosociologia 42(1):71-95

Dobrowolska D (2008) Growth and development of silver fir (Abies alba Mill.) regeneration and restoration of the species in the Karkonosze Mountains. J For Sci 54(9):398-408

Dobrowolska D (2010) The role of disturbances in forest regeneration. Leœne Prace Badawcze (For Res Pap) 71(4):391-405

Duchesneau R, Lesage I, Messier C, Morin H (2001) Effects of light and intraspecific competition on growth and crown morphology of two size classes of understory balsam fir saplings. For Ecol Manag 140(2):215-225

Enquist BJ (2002) Universal scaling in tree and vascular plant allometry: toward a general quantitative theory linking plant form and function from cells to ecosystems. Tree Physiol 22(15-16):1045-1064

Farquhar GD, Ehleringer JR, Hubick KT (1989) Carbon isotope discrimination and photosynthesis. Annu Rev Plant Biol 40(1):503-537

Fellner H, Dirnberger GF, Sterba H (2016) Specific leaf area of European Larch (Larix decidua Mill.) Trees 30:1237-1244. doi:10.1007/ s00468-016-1361-1

Givnish TJ (1995) Plant stems: biomechanical adaptation for energy capture and influence on species distributions. In: Gartner BL (ed) Plant Stems. Academic Press, San Diego, pp 3-49

Grace JB, Anderson TM, Olff H, Scheiner SM (2010) On the specification of structural equation models for ecological systems. Ecol Monogr 80(1):67-87. doi:10.1890/09-0464.1

Grassi G, Giannini R (2005) Influence of light and competition on crown and shoot morphological parameters of Norway spruce and silver fir saplings. Ann For Sci 62(3):269-274. doi:10.1051/forest:2005019

Grossnickle SC, Major JE, Arnott JT, Lemay VM (1991) Stock quality assessment through an integrated approach. New For 5(2):77-91. doi:10.1007/bf00029300

Hillman J (1984) Apical dominance. In: Wilkins M (ed) Advanced plant physiology. Pitman, London, pp 127-148

$\mathrm{Hu}$ LT, Bentler PM (1999) Cutoff criteria for fit indexes in covariance structure analysis: conventional criteria versus new alternatives. Struct Equ Model 6(1):1-55. doi:10.1080/10705519909540118

Hubbard RM, Bond BJ, Ryan MG (1999) Evidence that hydraulic conductance limits photosynthesis in old Pinus ponderosa trees. Tree Physiol 19(3):165-172. doi:10.1093/treephys/19.3.165

Iida Y, Poorter L, Sterck F, Kassim AR, Potts MD, Kubo T, Kohyama TS (2014) Linking size-dependent growth and mortality with architectural traits across 145 co-occurring tropical tree species. Ecology 95: 353-363

Iovino F, Menguzzato G (1993) L'abete bianco sull'Appennino Lucano. Ann Accad Ital Sci For 42:185-214

King DA (1990) The adaptive significance of tree height. Am Nat 135(6): $809-828$

Küppers M (1989) Ecological significance of aboveground architectural patterns in woody plants: a question of cost-benefit relationships. Trends Ecol Evol 4:375-379

Küppers M (1994) Canopy gaps: competitive light interception and economic space filling-a matter of whole-plant allocation. In: Caldwell MM, Pearcy RW (eds) Exploitation of environmental heterogeneity by plants: ecophysiological processes above- and belowground. Academic Press, San Diego, pp 111-144

Laughlin DC, Abella SR (2007) Abiotic and biotic factors explain independent gradients of plant community composition in ponderosa 
pine forests. Ecol Model 205(1-2):231-240. doi:10.1016/j. ecolmodel.2007.02.018

Lavorel S, Grigulis K (2012) How fundamental plant functional trait relationships scale-up to trade-offs and synergies in ecosystem services. J Ecol 100(1):128-140. doi:10.1111/j.1365-2745.2011. 01914. $\mathrm{x}$

Linares JC, Carreira JA (2009) Temperate-like stand dynamics in relict Mediterranean-fir (Abies pinsapo, Boiss.) forests from Southern Spain. Ann For Sci 66(6):1-10

Marshall JD, Monserud RA (2003) Foliage height influences specific leaf area of three conifer species. Can J For Res 33(1):164-170. doi:10. $1139 / \mathrm{x} 02-158$

McDowell NG, Bond BJ, Dickman LT, Ryan MG, Whitehead D (2011) Relationships between tree height and carbon isotope discrimination. In: Meinzer CF, Lachenbruch B, Dawson ET (eds) Size- and age-related changes in tree structure and function. Springer Netherlands, Dordrecht, pp 255-286

McGill BJ, Enquist BJ, Weiher E, Westoby M (2006) Rebuilding community ecology from functional traits. Trends Ecol Evol 21(4):178185. doi:10.1016/j.tree.2006.02.002.

Meinzer FC, Bond BJ, Karanian JA (2008) Biophysical constraints on leaf expansion in a tall conifer. Tree Physiol 28(2):197-206. doi:10. 1093/treephys/28.2.197

Mexal JG, Landis TD (1990) Target seedling concepts: height and diameter. In: Rose R, Campbell SJ, Landis TD (Ed) Target seedling symposium: proceedings, combined meeting of the western forest nursery associations; 1990 August 13-17; Roseburg, Oregon. Gen. Tech. Rep. RM-GTR-200. Fort Collins, CO: U.S. Department of Agriculture, Forest Service, Rocky Mountain Forest and Range Experiment Station, pp. 17-35

Meziane D, Shipley B (2001) Direct and indirect relationships between specific leaf area, leaf nitrogen and leaf gas exchange. Effects of irradiance and nutrient supply. Ann Bot 88(5):915-927. doi:10. 1006/anbo.2001.1536

Moles AT, Falster DS, Leishman MR, Westoby M (2004) Small-seeded species produce more seeds per square metre of canopy per year, but not per individual per lifetime. J Ecol 92(3):384-396

Nevitt J, Hancock GR (2001) Performance of bootstrapping approaches to model test statistics and parameter standard error estimation in structural equation modeling. Struct Equ Model 8(3):353-377

Niinemets Ü, Kull O, Tenhunen JD (1998) An analysis of light effects on foliar morphology, physiology, and light interception in temperate deciduous woody species of contrasting shade tolerance. Tree Physiol 18(10):681-696. doi:10.1093/treephys/18.10.681

Olson ME, Anfodillo T, Rosell JA, Petit G, Crivellaro A, Isnard S, LeonGomez C, Alvarado-Cardenas LO, Castorena M (2014) Universal hydraulics of the flowering plants: vessel diameter scales with stem length across angiosperm lineages, habits and climates. Ecol Lett 17(8):988-997. doi:10.1111/ele.12302

Olsson UH, Foss T, Troye SV, Howell RD (2000) The performance of ML, GLS, and WLS estimation in structural equation modeling under conditions of misspecification and nonnormality. Struct Equ Model 7(4):557-595. doi:10.1207/S15328007SEM0704 3

Piotti A, Leonarduzzi C, Postolache D, Bagnoli F, Spanu I, Brousseau L, Urbinati C, Leonardi S, Vendramin GG (2017) Unexpected scenarios from Mediterranean refugial areas: disentangling complex demographic dynamics along the Apennine distribution of silver fir. $\mathrm{J}$ Biogeogr. doi:10.1111/jbi.13011

Poorter H, Niinemets Ü, Poorter L, Wright IJ, Villar R (2009) Causes and consequences of variation in leaf mass per area (LMA): a metaanalysis. New Phytol 182(3):565-588. doi:10.1111/j.1469-8137. 2009.02830.x

Development Core Team R (2015) R: a language and environment for statistical computing [online]. R Foundation for Statistical Computing, Vienna
Ripullone F, Gentilesca T, Lauteri M, Rita A, Rivelli AR, Schettino A, Borghetti M (2016) Apical dominance ratio as an indicator of the growth conditions favouring Abies alba natural regeneration under Mediterranean environment. Eur J For Res 135(2):377-387. doi:10. 1007/s10342-016-0941-3

Robakowski P, Wyka T, Samardakiewicz S, Kierzkowski D (2004) Growth, photosynthesis, and needle structure of silver fir (Abies alba Mill.) seedlings under different canopies. For Ecol Manag 201(2-3):211-227. doi:10.1016/j.foreco.2004.06.029

Rosseel Y (2012) lavaan: an R package for structural equation modeling. J Stat Softw 48(2):1-36

Rüger N, Wirth C, Wright SJ, Condit R (2012) Functional traits explain light and size response of growth rates in tropical tree species. Ecology 93:2626-2636. doi:10.1890/12-0622.1

Sánchez-Gómez D, Valladares F, Zavala MA (2006) Functional traits and plasticity in response to light in seedlings of four Iberian forest tree species. Tree Physiol 26:1425-1433

Satorra A, Bentler P (1994) Corrections to test statistics and standard errors in covariance structure analysis. In: von Eye A, Clogg C (eds) Latent variables analysis: applications for developmental research. SAGE Publication, Inc., Thousand Oaks, pp 399-419

Shipley B, Vile D, Garnier E, Wright IJ, Poorter H (2005) Functional linkages between leaf traits and net photosynthetic rate: reconciling empirical and mechanistic models. Funct Ecol 19(4):602-615. doi: 10.1111/j.1365-2435.2005.01008.x

Shipley B, Lechowicz MJ, Wright I, Reich PB (2006) Fundamental tradeoffs generating the worldwide leaf economics spectrum. Ecology 87(3):535-541

Spasojevic MJ, Grace JB, Harrison S, Damschen EI (2014) Functional diversity supports the physiological tolerance hypothesis for plant species richness along climatic gradients. J Ecol 102(2):447-455

Steiger JH (1990) Structural model evaluation and modification: an interval estimation approach. Multivar Behav Res 25(2):173-180. doi: $10.1207 / \mathrm{s} 15327906 \mathrm{mbr} 2502 \_4$

Tcherkez G, Hodges M (2008) How stable isotopes may help to elucidate primary nitrogen metabolism and its interaction with (photo)respiration in C3 leaves. J Exp Bot 59(7):1685-1693. doi: 10.1093/jxb/erm115

Thompson BE (1985) Seedling morphological evaluation: what you can tell by looking. In: Duryea ML (ed) Evaluating seedling quality: principles, procedures, and predictive abilities of major tests. Forest research laboratory. Oregon State University, Corvallis

Valladares F, Niinemets U (2007) The architecture of plant crowns: from design rules to light capture and performance. In: Pugnaire FI, Valladares F (eds) Functional plant ecology. CRC Press, Broken Sound Parkway NW, pp 101-149

Valladares F, Wright SJ, Lasso E, Kitajima K, Pearcy RW (2000) Plastic phenotypic response to light of 16 congeneric shrubs from a Panamanian rainforest. Ecology 81:1925-1936

Walters MB, Reich PB (2000) Seed size, nitrogen supply, and growth rate affect tree seedling survival in deep shade. Ecology 81(7):1887-1901

Warren CR, Ethier GJ, Livingston NJ, Grant NJ, Turpin DH, Harrison DL, Black TA (2003) Transfer conductance in second growth Douglas-fir (Pseudotsuga menziesii (Mirb.)Franco) canopies. Plant Cell Environ 26(8):1215-1227. doi:10.1046/j.1365-3040.2003. 01044.x

Westoby M, Wright IJ (2006) Land-plant ecology on the basis of functional traits. Trends Ecol Evol 21(5):261-268. doi:10.1016/j.tree. 2006.02.004

Wright IJ, Reich PB, Westoby M, Ackerly DD, Baruch Z, Bongers F, Cavender-Bares J, Chapin T, Cornelissen JHC, Diemer M, Flexas J, Garnier E, Groom PK, Gulias J, Hikosaka K, Lamont BB, Lee T, Lee W, Lusk C, Midgley JJ, Navas M-L, Niinemets Ü, Oleksyn J, Osada N, Poorter H, Poot P, Prior L, Pyankov VI, Roumet C, 
Thomas SC, Tjoelker MG, Veneklaas EJ, Villar R (2004) The worldwide leaf economics spectrum. Nature 428:821-827. doi:10. 1038/nature02403

Yakir D, Israeli Y (1995) Reduced solar irradiance effects on net primary productivity (NPP) and the $\delta^{13} \mathrm{C}$ and $\delta^{18} \mathrm{O}$ values in plantations of Musa sp., Musaceae. Geochim Cosmochim Acta 59(10):2149-2151
Zanne AE, Falster DS (2010) Plant functional traits-linkages among stem anatomy, plant performance and life history. New Phytol 185(2):348-351. doi:10.1111/j.1469-8137.2009.03135.x 